\title{
The influence of the rootstock on the formation of quality indicators of sweet cherry variety Alexandria
}

\author{
Tatiana Prichko ${ }^{I *}$, and Valery Sivoplyasov ${ }^{2}$ \\ ${ }^{1}$ Federal State Budget Scientific Institution «North Caucasian Federal Scientific Center of Horticulture, \\ Viticulture, Wine-making», 39 str. 40 Let Pobedy, Krasnodar, 350901, Russia \\ ${ }^{2}$ Krymsk EBS VIR Branch, 12 str. Vavilov, Krymsk, 353384, Russia
}

\begin{abstract}
The tested 27 samples of sweet cherry Alexandria variety grown on rootstocks with different growth rates (low-growing, medium and vigorous) had different indicators both in marketable conditions and in the content of a complex of biologically active substances - sugars, acids, vitamins. According to the level of accumulation of substances that form the nutritional, therapeutic and prophylactic properties of sweet cherry fruits, variety-rootstock combinations have been identified that provide an improvement in the quality indicators of fruits: ANT x Maaka 9-8, ANTD 12/20, S 33, Gegard, ANT x 2-77-1, ANT self-fertile 17, ANT w / n 5, Chufut Kale.
\end{abstract}

\section{Introduction}

Sweet cherry is one of the most popular stone fruit crops cultivated in the south of Russia, which is especially popular due to its early time of fruits ripening. Cherry plantations are mainly concentrated in the southern zone of our country with favorable growing conditions $[1,2]$.

Sweet cherry opens the fruit season, ripening earlier than other fruit crops. Its fruits are eaten fresh, and only a small part is used for industrial processing [3]. Cherry fruits are distinguished by a high content of sugars, which are mainly represented by fructose and glucose, which enhances its dietary properties. The palatability of the fruit is characterized by a favorable combination of sugars with acids, represented by malic, citric, succinic, and lactic acids.

Sweet cherry is becoming a very popular crop and is gaining more and more markets in Russia and abroad. The productivity of sweet cherry plantations depends on the varietal composition and selection of rootstocks $[4,5]$. The use of various rootstocks (low, medium, above medium vigor) is very important for the cultivation of sweet cherries. The correct choice of rootstock in combination with the use of the best varieties of sweet cherry allows to reduce the growth rate of trees, to reduce the volume of the crown, to improve the quality of fruits $[6,7,8]$. To solve this problem, it is necessary to use clonal rootstocks, which make it possible to improve adaptability to stress factors while increasing the yield of plantings [912]. The use of clonal rootstocks in gardens of an intensive type with a growth force above 
average is interesting in conditions in the south of Russia using modern formations where guaranteed irrigation is impossible. [13-16].

The purpose of this work is to select clonal rootstocks of different growth rates for the Alexandria variety, ensuring the production of fruits with high marketable indicators.

\section{Materials and Methods}

Objects of research: 27 samples of sweet cherry fruits grown on rootstocks of different growth rates, growing at the Crimean Experimental Station. The cherry orchard was planted in 2015 according to the scheme $5.0 \times 2.0 \mathrm{~m}$. The tree formation was according to the type of Kim Green Bush, consisting of several vertical conductors - leaders.

The weather conditions during the period of the garden's growth were varied: the amount of precipitation was $657 \mathrm{~mm}$ (mainly October-April); during the growing season, there was a moisture deficit in the soil. Observations and counts were carried out according to the "Program and methodology for the study of varieties of fruit, berry and nut crops."

Methods of biometric statistics were used for mathematical processing (BA Dospekhov "Methodology of field experience", 1979), Microsoft Excel, Statistika-99.

\section{Results and Discussion}

When studying varietal-rootstock combinations in the sweet cherry variety Alexandria, the RVL 9 rootstock was taken as control. A high setting of flower buds was noted in lowgrowing rootstocks (ANT 14-21-33, ANT self-fertile 17), medium-sized rootstocks (ANT 1/148 9/10, S-85, ANT S 36), vigorous rootstocks (S-3, Kamensk 18).

The rootstock forms above the average vigor of growth (ANT11 / 74, ANT S56, Kamensk 18 , ANT w/n 5, S-3) were early-growing and had a yield from 12.1 to $15.4 \mathrm{~kg} /$ tree, which was more than in control.

One of the modern and necessary methods of growing fruit trees are various rootstocks, which can affect the biochemical indicators of the quality of the fruit.

The influence of various variety-rootstock combinations on the formation of commercial qualities of sweet cherry fruits (shape, size, color, density) is noted. Fruit weight is a characteristic feature of the variety; however, to a certain extent this indicator is due to the type of rootstock and its strength of growth.

In the experiments, the weight of the fruits varied from 7.4 to $11.5 \mathrm{~g}$. Fruits grown on a medium and above average growth vigor rootstocks, such as ANT self-fertile 15-38, ANT x Maaka 9-8, Gegard, ANT v.st. 2-77-1, ANT s 56, ANT 2/7, A 74-8, with a fruit weight of 11.5-10.0 g.

It should be noted that, in terms of commercial quality, the studied sweet cherry fruits grown on different rootstocks belonged to the highest commercial grade (the largest transverse diameter was more than $20 \mathrm{~mm}$ ) and varied from $26.0 \mathrm{~mm}$ (ANT b/n 16) to 30 mm (ANT x Maaka 9-8 and ANT self-fertile 15-38) (table 1).

The shape of cherry fruits in these fruits is rounded (shape index 0.81-0.93 p.u.).

The amount of dry matter and sugars, which determines the degree of fruit ripeness, is formed in sweet cherry fruits in different ways. There was a significant variation of these indicators depending on the variety-rootstock combination, which amounted to $15.4 \%$ $18.2 \%$ (dry matter) and $10.8 \%-12.4 \%$ (sugars). The maximum accumulation of soluble solids (RSV) (17.5-18.2\%) and sugars (11.9-12.4\%) was observed in fruits grown on rootstocks: S33, Geghard, ANT x vs.t. 2-77-1, ANT 213. 
Table 1. Technical indicators of sweet cherry fruits depending on the type of rootstock, variety Alexandria

\begin{tabular}{|c|c|c|c|c|}
\hline Rootstock & Weight, $g$ & $\begin{array}{c}\text { Height } \\
\mathrm{mm}\end{array}$ & $\begin{array}{c}\text { Diameter, } \\
\mathrm{mm}\end{array}$ & $\begin{array}{l}\text { Index } \\
\text { shape }\end{array}$ \\
\hline RVL 9 (control) & 9.8 & 24.0 & 27.5 & 0.87 \\
\hline \multicolumn{5}{|c|}{ Rootstocks above average vigor } \\
\hline $1-134 \mathrm{~A} 30 \mathrm{~A}$ & 9.70 & 24.0 & 27.0 & 0.89 \\
\hline A $74-8$ & 10.01 & 24.0 & 27.5 & 0.87 \\
\hline ANT 11/74 & 9.62 & 25.0 & 29.0 & 0.86 \\
\hline ANT $2 / 7$ & 10.21 & 24.0 & 29.0 & 0.83 \\
\hline ANT c 56 & 10.43 & 25.0 & 29.0 & 0.86 \\
\hline ANT x v.st 2-77-1 & 10.70 & 24.0 & 29.0 & 0.83 \\
\hline ANT w/n 5 & 9.91 & 24.0 & 27.0 & 0.89 \\
\hline Jermuk 30 & 9.32 & 23.0 & 26.5 & 0.87 \\
\hline Kamensk 16 & 9.30 & 23.2 & 27.5 & 0.84 \\
\hline Kamensk 18 & 9.81 & 24.0 & 27.5 & 0.87 \\
\hline S-3 & 9.74 & 24.0 & 29.0 & 0.83 \\
\hline average & 9.87 & 24.0 & 28.0 & 0.86 \\
\hline \multicolumn{5}{|c|}{ Medium growth vigor rootstocks } \\
\hline ANT 1/148 9/10 c 479 & 9.20 & 24.0 & 28.0 & 0.86 \\
\hline ANT 213 & 9.91 & 23.0 & 28.5 & 0.81 \\
\hline ANT $\mathrm{w} / n 16$ & 8.40 & 24.0 & 26.0 & 0.92 \\
\hline ANT S36 & 9.42 & 24.5 & 27.0 & 0.91 \\
\hline ANT self-fertile $15-38$ & 11.52 & 25.0 & 30.0 & 0.83 \\
\hline ANT A 30 & 9.00 & 23.0 & 26.5 & 0.87 \\
\hline $\mathrm{ANT} \mathrm{w} / n 13$ & 7.43 & 22.5 & 26.0 & 0.87 \\
\hline ANTD $12 / 20$ & 9.81 & 25.0 & 27.0 & 0.93 \\
\hline ANT $x$ Маака 9-8 & 11.10 & 25.5 & 30.0 & 0.85 \\
\hline S-85 & 9.62 & 23.0 & 28.0 & 0.82 \\
\hline S33 & 8.73 & 23.5 & 27.0 & 0.87 \\
\hline Gegard & 10.51 & 25.0 & 28.0 & 0.89 \\
\hline Chufut Kale & 9.60 & 25.0 & 28.0 & 0.89 \\
\hline average & 9.55 & 24.1 & 27.7 & 0.87 \\
\hline \multicolumn{5}{|c|}{ Low growth vigor rootstocks } \\
\hline ANT 14-21-33 & 8.61 & 22.0 & 27.0 & 0.81 \\
\hline ANT self-fertile 17 & 9.32 & 24.0 & 28.0 & 0.86 \\
\hline average & 8.96 & 23.0 & 27.5 & 0.84 \\
\hline
\end{tabular}

The acidity in fruits, depending on the rootstock, varied from $0.50 \%$ (rootstock S- 85 , Jermuk 30, Chufut Kale, ANT S36, etc.) to $0.64 \%$ (ANT 213) (Table 2).

Cherry fruits had a sweet-sour taste (sugar-acid index less than 20 p.u.) and sweet taste (sugar-acid index more than 22.1 p.u.), which was observed in cherries grown on the rootstocks of Chufut Kale, Jermuk 30, ANTD12/20, S 39-4, Gegard.

The results of studies on the vitamin composition of sweet cherry fruits showed that the amount of ascorbic acid, depending on the rootstock in the fruit, ranges from $6.8 \mathrm{mg} / 100 \mathrm{~g}$ to $9.8 \mathrm{mg} / 100 \mathrm{~g}$. The amount of vitamin $\mathbf{C}$ in cherries grown on rootstocks ANTD12/20, ANT w/n 5, ANT self-fertile 17 exceeded the average content $(8.3 \mathrm{mg} / 100 \mathrm{~g})$ and amounted to $9.7-$ $9.8 \mathrm{mg} / 100 \mathrm{~g}$. 
Table 2. Chemical composition of sweet cherry fruits depending on the type of rootstock, variety Alexandria

\begin{tabular}{|c|c|c|c|c|c|c|c|}
\hline Rootstook & $\begin{array}{c}\text { Dry } \\
\text { matter } \\
, \%\end{array}$ & $\begin{array}{l}\text { Sugars, } \\
\%\end{array}$ & $\begin{array}{c}\text { Acidit } \\
y, \%\end{array}$ & $\begin{array}{l}S / A \\
\text { ind }\end{array}$ & $\begin{array}{c}\text { Vitamin } \\
\boldsymbol{C}, \\
\mathrm{mg} / 100 \mathrm{~g}\end{array}$ & $\begin{array}{c}\text { Vitamin } \\
\boldsymbol{P}, \\
\mathrm{mg} / 100 \mathrm{~g}\end{array}$ & $\begin{array}{c}\text { Anthocyani } \\
n s, \mathrm{mg} / 100 \\
\mathrm{~g}\end{array}$ \\
\hline $\begin{array}{l}\text { RVL 9 } \\
\text { (control) }\end{array}$ & 15.5 & 10.5 & 0.54 & 19.5 & 8.3 & 52.8 & 143.4 \\
\hline \multicolumn{8}{|c|}{ Rootstocks above average vigor } \\
\hline 1-134A 30A & 15.4 & 10.5 & 0.50 & 20.9 & 7.4 & 48.0 & 121.4 \\
\hline A $74-8$ & 15.2 & 10.3 & 0.57 & 18.1 & 7.0 & 54.0 & 120.6 \\
\hline ANT $11 / 74$ & 16.0 & 10.9 & 0.55 & 19.8 & 6.8 & 50.8 & 116.9 \\
\hline ANT 2/7 & 15.7 & 10.7 & 0.60 & 17.8 & 7.9 & 41.8 & 121.4 \\
\hline ANT c 56 & 16.2 & 11.0 & 0.58 & 19.0 & 6.8 & 54.0 & 121.4 \\
\hline $\begin{array}{l}\text { ANT } x \text { v.st. } \\
2-77-1\end{array}$ & 17.5 & 11.9 & 0.57 & 20.9 & 7.4 & 50.8 & 130.4 \\
\hline ANT w/n 5 & 17.1 & 11.6 & 0.59 & 19.7 & 9.7 & 66.6 & 134.4 \\
\hline Jermuk 30 & 16.4 & 11.2 & 0.50 & 22.3 & 7.0 & 41.8 & 149.3 \\
\hline Kamensk 16 & 16.9 & 11.5 & 0.55 & 20.9 & 7.0 & 54.0 & 168.0 \\
\hline Kamensk 18 & 15.8 & 10.7 & 0.55 & 19.5 & 8.1 & 57.2 & 155.7 \\
\hline S-3 & 16.7 & 11.4 & 0.57 & 19.9 & 7.2 & 60.4 & 164.9 \\
\hline average & 16.3 & 11.1 & 0.56 & 19.9 & 7.5 & 52.7 & 136.8 \\
\hline \multicolumn{8}{|c|}{ Medium growth vigor rootstocks } \\
\hline $\begin{array}{l}\text { ANT } 1 / 148 \\
9 / 10 \text { c } 479\end{array}$ & 16.3 & 11.1 & 0.55 & 20.2 & 7.0 & 38.6 & 218.4 \\
\hline ANT 213 & 17.5 & 11.9 & 0.64 & 18.6 & 8.4 & 57.2 & 136.5 \\
\hline $\mathrm{ANT} \mathrm{w} / n 16$ & 15.5 & 10.5 & 0.49 & 21.5 & 7.6 & 54.0 & 155.7 \\
\hline ANT S36 & 15.4 & 10.8 & 0.50 & 21.6 & 9.0 & 48.0 & 120.5 \\
\hline $\begin{array}{l}\text { ANT self- } \\
\text { fertile } 15-38\end{array}$ & 17.0 & 11.6 & 0.60 & 19.3 & 7.4 & 41.8 & 143.4 \\
\hline ANT A 30 & 15.4 & 10.5 & 0.55 & 19.0 & 7.4 & 57.2 & 143.4 \\
\hline ANT w/n 13 & 15.8 & 10.7 & 0.60 & 17.9 & 6.8 & 48.0 & 209.4 \\
\hline ANTD12/20 & 17.2 & 11.7 & 0.52 & 22.5 & 9.8 & 48.0 & 155.7 \\
\hline $\begin{array}{l}\text { ANT } x \\
\text { Маака 9-8 }\end{array}$ & 17.1 & 11.6 & 0.55 & 21.1 & 7.7 & 63.4 & 172.5 \\
\hline S-85 & 15.4 & 10.5 & 0.50 & 20.9 & 7.5 & 38.6 & 149.3 \\
\hline S33 & 17.6 & 12.2 & 0.59 & 20.6 & 8.1 & 66.6 & 236.4 \\
\hline Gegard & 17.8 & 12.1 & 0.53 & 22.8 & 7.4 & 57.2 & 143.4 \\
\hline Chufut Kale & 15.5 & 10.5 & 0.50 & 22.1 & 8.1 & 63.4 & 121.4 \\
\hline average & 16.4 & 11.2 & 0.55 & 20.6 & 7.9 & 52.5 & 162.0 \\
\hline \multicolumn{8}{|c|}{ Low growth vigor rootstocks } \\
\hline $\begin{array}{l}\text { ANT 14-21- } \\
33\end{array}$ & 15.4 & 10.5 & 0.50 & 20.9 & 7.2 & 44.8 & 137.4 \\
\hline $\begin{array}{l}\text { ANT self- } \\
\text { fertile } 17\end{array}$ & 15.7 & 10.7 & 0.50 & 21.4 & 9.7 & 44.8 & 116.3 \\
\hline average & 15.6 & 10.6 & 0.50 & 21.2 & 8.5 & 44.8 & 126.9 \\
\hline
\end{tabular}

The vitamin $\mathbf{P}$ content varied from $38.6 \mathrm{mg} / 100 \mathrm{~g}$ to $66.6 \mathrm{mg} / 100$. More than 63.4 $\mathrm{mg} / 100 \mathrm{~g}$ of $\mathbf{P}$-active catechins contained cherry fruits grown on the rootstocks of Chufut Kale, ANT x Maaka 9-8, S33, ANT w / n 5, S 39-4. 
The color of the skin of the studied varieties of cherries is from dark red to red. Fruits grown on rootstocks with average and above average vigor of growth differ significantly in their anthocyanin content: S33 (236.4 mg/100 g), ANT 1/148 9/10 c 479 (218.4 mg/100 g), ANT w/n 13 (209.4 mg/100 g), ANT x Maaka 9-8 (172.5 mg/100 g), Kamensk 16 (168.0 $\mathrm{mg} / 100 \mathrm{~g})$ and S-3 (164.9 mg/100 g), having a more intense color.

\section{Conclusion}

In terms of commercial qualities, with a mass of cherry fruits of the Alexandria variety of more than $10 \mathrm{~g}$ and the amount of accumulated substances that form taste, nutritional value, the following variety-rootstock combinations can be distinguished, which make it possible to obtain high-quality fruits grown on rootstocks: ANT x Maaka 9-8, ANTD 12/20, C 33, Geghard, ANT x v.st. 2-77-1, ANT self-fertile 17, ANT w/n 5, Chufut Kale.

\section{References}

1. T. G. Prichko, E. M. Alyokhina, V.G. Ermolenko, Adaptive sweet cherry varieties and modern technologies of its cultivation in conditions of the South of Russia, 85 (NCFSCHVW, Krasnodar, 2019)

2. O. V. Eremina, G.N. Zhukov., V. M. Karenik, Proceedings of the Scientific and Practical conference of Kuban department of VSG\&B, 167-168 (2012)

3. E. Kullaj, In: M.W. Siddiqui (ed) Preharvest Modulation of Postharvest Fruit and Vegetable Quality, 189-207 (Academic Press, 2018) https://doi.org/10.1016/B978-0-12809807-3.00008-1

4. J. Giné-Bordonaba, G. Echeverria, D. Ubach, I. Aguiló-Aguayo, M.L. López, C. Larrigaudière, Plant Physiol. Biochem., 111, 216-225 (2017) https://doi.org/10.1016/j.plaphy.2016.12.002

5. I. Opazo, G. Toro, A. Salvatierra, C. Pastenes, P. Pimentel, Agric. Water Manag., 228, 105897 (2020) https://doi.org/10.1016/j.agwat.2019.105897

6. J.U. Mgbechi-Ezeri, K.B. Johnson, L.D. Porter, N.C. Oraguzie, Crop Prot., 112, 246-251 (2018) https://doi.org/10.1016/j.cropro.2018.06.009

7. G. Reig, C. Font i Forcada, L, Mestre, J.A. Betrán, M.Á. Moreno, Sci. Hortic., 234, 193200 (2018) https://doi.org/10.1016/j.scienta.2018.02.037

8. L. E. Arroyo, M. E. Daorden, G. H. Valentini, G. D. Lucio Cervigni, Sci. Hortic., 198, 385-397 (2016) https://doi.org/10.1016/j.scienta.2015.11.017

9. F. Kappel, G. Lang, A. Azarenko, T. Factcau, A. Gaus, R. Godin, T. Lindstrom, R. Nunez-Elisea, R. Pokharel, M. Whiting, C. Hampson, J. Amer. Pomol. Soc., 67(4), 186195 (2013) https://www.researchgate.net/publication/297313474

10. J.P. Londo, E.J. Wettberg, A.J. Miller, Garden. trends, 21(5), 418-437 (2016) https://doi.org/10.1016/j.tplants.2015.11.008

11. T. Milošević, N. Milošević, J. Mladenović, Sci. Hortic., 265, 109236 (2020) https://doi.org/10.1016/j.scienta.2020.109236

12. S. Bijelić, B. Bogdanović, S. Cerović, B. Gološin, J. Ninić-Todorović, Letop. Nauč. Rad., 38(1), 29-37 (2014) http://scindeks.ceon.rs/Article.aspx?artid=0546-82641401029B

13. S. Correia, R. Schouten, A.P. Silva, B. Gonçalves, Front. Plant Sci., 8, 2166 (2017) https://doi.org/10.3389/fpls.2017.02166

14. G. Bujdosó, L. Magyar, K. Hrotkó, Sci. Hortic. 256, 108613 (2019) https://doi.org/10.1016/j.scienta.2019.108613

15. G. Bujdosó, K. Hrotkó, Acta Hortic., 1235, 207-212 (2019) http://doi.org/10.17660/ActaHortic.2019.1235.27 